This is an electronic reprint of the original article. This reprint may differ from the original in pagination and typographic detail.

Author(s): Sivunen, Anu

Title: $\quad$ Presence and Absence in Global Virtual Team Meetings : Physical, Virtual, and Social Dimensions

Year: $\quad 2016$

Version:

Please cite the original version:

Sivunen, A. (2016). Presence and Absence in Global Virtual Team Meetings : Physical, Virtual, and Social Dimensions. In J. Webster, \& K. Randle (Eds.), Virtual Workers and the Global Labour Market (pp. 199-217). Palgrave Macmillan. Dynamics of Virtual Work. https://doi.org/10.1057/978-1-137-47919-8_10

All material supplied via JYX is protected by copyright and other intellectual property rights, and duplication or sale of all or part of any of the repository collections is not permitted, except that material may be duplicated by you for your research use or educational purposes in electronic or print form. You must obtain permission for any other use. Electronic or print copies may not be offered, whether for sale or otherwise to anyone who is not an authorised user. 


\title{
Presence and absence in global virtual team meetings: Physical, virtual and social dimensions
}

Anu Sivunen, Ph.D.

Department of Language and Communication Studies (L)

P.O.Box 35, FI-40014 University of Jyväskylä, Finland

anu.e.sivunen@jyu.fi

\begin{abstract}
Global virtual work is commonly organised around virtual meetings. As virtual team members often belong to multiple groups in their work, finding time for global team meetings may be challenging due to competing priorities and roles as well as different time zones and schedules. Furthermore, social presence does not automatically emerge based on physical or virtual presence. Therefore, the notions of being physically, virtually and socially present or absent in global team meetings are important, and affect the collaboration of global work groups. These different dimensions of presence and absence and their nature as fluctuating phenomena have not yet been scrutinised in virtual work literature. This chapter examines the dimensions of presence and absence in global virtual work and presents a propositional model to study predictors and effects of presence and absence in virtual meetings. The physical, virtual and social dimensions of presence are examined in both co-located and virtual settings.
\end{abstract}

This is the author's accepted manuscript of the published article:

Sivunen, A. (2016). Presence and absence in global virtual team meetings: Physical, virtual, and social dimensions. In J. Webster \& K. Randle (Eds.) Virtual Workers and the Global Labour Market (pp. 199-217). Palgrave Macmillan UK. 
Introduction

Global virtual work, defined as interdependent work conducted in different geographical locations with the help of communication technologies (Martins et al., 2004), is often organised around virtual meetings. Members of global work groups may carry out some of their tasks independently, but several tasks such as brainstorming, co-designing and decision-making are often performed together, either in co-located sub-group meetings or in virtual meetings. As global team members often belong to multiple groups in their work (see for example O'Leary and Mortensen, 2010), scheduling global team meetings and being physically or virtually present, but also socially attentive and engaged in them, may be challenging due to competing individual priorities, roles and routines, as well as different work and leisure time related cycles, time zones and schedules (Ballard et al., 2008; Pendharkar, 2013; Swigger et al., 2012). Therefore, the question of presence and absence in global virtual team meetings plays a central role and affects the quality of collaboration in global work groups. It is one of the team leader's responsibilities to ensure that team members can be present and available in virtual team meetings, but it is also important to the team members themselves as well as to the accomplishment of their teamwork in general, that they and other team members are present and available in virtual team meetings. Presence or absence in virtual meetings plays a role in accomplishing the work as well as impacting other members' presence and availability in these meetings (Panteli, 2004).

Presence is a well-studied concept especially in terms of virtual collaboration. Short, Williams and Christie (1976) were the first to study telecommunication and used the term "social presence" to describe the phenomena that occurs between interlocutors that are not physically present but share a sense of presence by having 
a conversation via technology. However, the concept of social presence became more equivocal after it was applied to mediated settings. As Biocca, Harms and Burgoon (2003) suggest, a more correct term for such phenomena could have been 'mediated social presence'. Still, from the introduction of a theory of social presence (Short et al. 1976), the theory has been developed around distanced and mediated settings, even though the definition and measures used when studying social presence could well be applied also to co-located context.

In this chapter I define presence as a phenomenon which may be physical, virtual, or social in nature and which may occur both in co-located and virtual settings. I use the terms physical, virtual and social presence to clarify the different settings where presence exists in global team meetings. Rather than the definition sometimes used for physical presence as 'being in the virtual place' (Biocca et al., 2003), the term physical presence in this paper implies that a global team member is co-located at a work site or meeting room with another sub-group member who is also attending the global virtual team meeting. Virtual presence, on the other hand, refers to a team member's availability for online collaboration during the meeting even though s/he is physically remote from the other participants. Social presence refers to the engaged and involved participation in the meeting that can happen both in co-located or virtual settings. These concepts need further exploration and are relevant especially in the framework of global virtual team meetings where team members collaborate both in face-to-face and mediated settings.

In contrast to the theories of presence, absence is something that has been much less studied in the context of global work. Absence is usually regarded as a physical leave or time away from work, meetings or other activities. Studies have focused on the predictors of sickness absence (Engström and Janson, 2009) as well 
as work-family balance and its effect on absence (Barthe et al., 2010) but this paradigm has led organisational studies scholars to overlook absence as a psychological and social phenomenon. However, absence can also be seen as a psychological phenomenon - 'social absence' (see also Kahn 1990; Kahn, 1992). From this perspective social presence and social absence are at opposite ends of a continuum. A team member may participate in a team meeting in a physical meeting room or in a virtual workspace, and be physically or virtually present, but more or less socially absent. There, I argue, social presence and social absence can also be intermittent in global team meetings and they can be described as fluctuating and ongoing phenomena (see also Sivunen and Nordbäck, 2015), whereas physical and virtual presence and absence are more static and dichotomous in nature.

In the next sections I review the literature on physical, virtual and social dimensions of presence and absence at work especially with regards to global virtual team meetings. I then focus on the perceived presence and absence of team members in global virtual team meetings and propose a model of the factors that predict and are caused by the perceptions of team members' presence and absence in those meetings. Finally, I present conclusions and discuss managerial implications related to the model presented.

Physical, Virtual and Social Presence

Presence is a theoretical but also empirically studied concept that has interested scholars in many fields, its roots lying in the early days of sociology and social psychology (see Biocca et al., 2003 for a review). Goffman (1963) refers to presence as something that can be accessed through sensory means when another 
participant is "within range" to be seen and heard (p. 17), and this awareness can vary from minimal to intense.

For some time, social psychologists have tested the effects that the physical presence of others has on the performance of individuals (see for example Bond and Titus, 1983 for review). This stream of research has also been applied to work contexts and studies exist, for example, on how the presence of experts and nonexperts affects the performance of individuals in certain tasks (Henchy and Glass, 1968) as well as on the effects of monitoring systems on employee performance (Aiello and Kolb, 1995; Stanton and Barnes-Farrell, 1996). There is also another, distinct stream of research related to physical presence at work, referred to as “presenteeism" (for example Halbesleben, Whitman, Crawford, 2014; Johns, 2010). Presenteeism refers to the condition in which employees who feel unable to take time off from work when ill, come to the office to be physically present at the workplace when they should be on a sick leave (see a review of definitions of presenteeism by Johns, 2010). Reasons for presenteeism have been found to emerge for example from perceived pressures from supervisors or co-workers (Grinyer and Singleton, 2000) and job insecurity (MacGregor, Cunningham and Caverley, 2008). Hence, one can argue that physical presence of others at work, or in a virtual team meeting, could occur for a number of reasons and has an impact on collaboration.

Research on virtual presence (as defined in this paper) is extensive. In one of the widely used classifications (Lombard and Ditton, 1997), three dimensions of (virtual) presence are presented that are relevant to the discussion in this chapter: 1) presence as social richness, 2) presence as transportation, and 3) presence as psychological immersion. Virtual presence as social richness focuses on the characteristics of the medium used in collaboration and how well they can transmit 
feelings of intimacy, sociability, and warmth between the collaborators. Virtual presence as transportation emphasises the idea that either the user is transported to another place ("being there"), another place and its objects are transported to the user ("it is here"), or the user is transported to the same place with his or her interlocutor ("we are here"). Virtual presence as psychological immersion refers to how strongly the users themselves feel engaged, involved or absorbed in the virtual space or with the media they are using (Lombard and Ditton, 1997).

Later research has merged the dimensions of (virtual) presence defined by Lombard and Ditton (1997) and separated social presence as an independent concept. In this tradition, social presence is defined as the psychological sense of being together with others in the mediated environment (see for example Shen and Khalifa, 2008). In contrast to this, I take a wider approach and see social presence as something that can also occur in physical settings. As social presence can also have important implications on collaboration in co-located settings, it should not be seen merely as a technology-mediated phenomenon. Others have also argued that a more correct term for the widely adopted concept "social presence" would be "mediated social presence" (Biocca et al., 2003). Hence, I follow the theoretical approach of Biocca and his co-authors (Biocca et al., 2001; 2003) and its later applications (Shen and Khalifa, 2008; Sivunen and Nordbäck, 2015) and redefine social presence as the sense of being with another in a mediated or co-located setting that can be manifested via copresence (as an embodied physical or virtual agent), psychological involvement and behavioural engagement. 
Absence is a construct that has been studied mostly as a physical state related to work. Research exists on employees' sickness absence (Barmby et al., 2002; Irvine, 2011) as well as on employees' leave from work due to other reasons, such as balancing of the work and family life (Barthe et al., 2010). Absence, which is related specifically to global work, is an area of study that needs further exploration. To distinguish between the different contexts and dimensions of absence, I use the terms physical, virtual and social absence, which refer to the different settings found in global work and especially in global virtual team meetings.

In contemporary global work settings where multiple team memberships exist, the employee faces simultaneous demands from several sources. Structural factors, or discontinuities, such as the geographical dispersion and time zone-differences between global team members (Chudoba et al., 2005), may lead to coordination challenges that cause team members' physical absence from global team meetings. Furthermore, these structural factors may become stressors to global team members (see for example Nurmi, 2010), which can in turn increase physical absence from global team meetings.

Virtual absence in global teamwork is in many ways similar to physical absence but there may be additional reasons for it. I define virtual absence in global team context as 'unavailability and non-attendance during global team meetings in a virtual workspace'. A global team member may be present at his or her work site with co-located sub-group members who are attending the meeting but cannot for whatever reason access the technology and be online with the global virtual team members. For example, the local infrastructure and network connections at team members' sites may cause difficulties in accessing the common virtual workspaces or 
meeting tools of global teams (Pauleen and Yoong, 2001). Global team members may also find some of the technologies challenging to use or they may have different preferences for the use of these tools (Sivunen and Valo, 2006). As virtual absence is often caused by the technology, it is also closely related to team member's skills and attitudes towards the collaboration media used in the meetings. Studies on collaboration technology use in organisations have covered issues such as employees' acceptance of the technology (Venkatesh et al., 2003) and attitudes towards it (Fulk et al., 1987). These factors, in addition to reasons causing physical absence (for example illness), may explain the reasons behind global team members' virtual absence from their team meetings.

Social absence at work can result from factors other than physical and virtual absence. Social absence in global team meetings could also be described as 'disengagement' (Kahn, 1990). In work settings disengagement can be defined as behaviours in which people leave out their personal selves during work role performances; they are not 'fully there' (Kahn, 1990; Kahn, 1992). According to the definition of disengagement by Kahn (1990), socially absent team members withdraw themselves cognitively and emotionally from their role performances in global meetings. They become inattentive and emotionally disconnected, and hide their feelings and opinions from other participants. Socially absent team members refrain from investing ideas, encouraging other team members or sharing visions and excitement of the work at hand.

However, studies of absence, especially as a psychological and social phenomenon at work are scarce (Kahn, 1990). Although studies exist that explore social absence for example as a symptom of a disease or grieving (Baxter et al., 2002; Betz and Thorngren, 2006), the term social absence or absent-mindedness 
(see for example Fisher and Hood, 1987), is not commonly used in organisational literature. However, I argue that social absence and social presence present different ends of a continuum; this axis can be seen as a range of states varying from full social absence through medium levels of attention and engagement to full social presence.

Predictors of Presence and Absence in Global Meetings

To be able to predict what might cause presence and absence in global team meetings and to anticipate their consequences for global virtual work I propose a model based on literature from various disciplines related to different dimensions of presence and absence in global virtual meetings (Figure 1). Based on this model I present the predictors of physical, virtual, and social presence and absence as well as discuss the outcomes of physical, virtual and social presence and absence for global work. 
mentioned in literature (for example Hinds and Weisband, 2003; Hinds and Cramton, 2014). Furthermore, different individual level factors, such as sickness or other leave, individual preferences, or power and resource issues may prevent team members' physical presence from global team meetings. The local team leader may not see the presence of his/her team member in a global team meeting as being as crucial as the global team leader may see it, or s/he may not want the local member to spend his/her resources in attending the meeting (see Nurmi et al., 2009 on different power contests in global teams). However, if the technology for global meetings is easily available and accessible, at least some of the structural predictors of physical absence can be overcome and members can be virtually present in the meetings.

Second, some of the structural predictors of virtual presence and virtual absence are somewhat similar to the physical presence and absence in global meetings. If a global meeting is taking place for example late at night in team member's location, it might be challenging for the team member to be present in the meeting either physically at a local site, or virtually via communication technology (see for example Ruppel et al., 2013). Virtual absence may be caused also by other structural or organisational predictors related to technology, such as problems in network infrastructure, team members' difficulties in accessing different collaboration technologies and their abilities to use them. However, in many cases the virtual tools provide possibilities for virtual presence when physical presence is not an option and the question of virtual presence or absence is more related to individual level predictors, such as the team member's attitudes and abilities to use the tools and fix possible technical problems that may occur during the meeting (see Figure 1).

Third, a great deal of research has focused on the enablers of social presence in virtual settings. The focus has been on the characteristics of the technology, such 
as their capacity to transmit information about participants' facial expressions and vocal cues (Short et al. 1976) and these characteristics have been found to be related to the experiences of social presence via virtual tools. However, in global meetings it is also common that a part of the group is physically present at the same location while attending the global meeting. In such situation, nonverbal communication may play a critical role in enhancing the social presence of the colocated sub-group participants, but these cues may not transmit adequately to the remote members due to technological limitations (see for example Sivunen and Nordbäck, 2015). Hence, structural and organisational factors predicting social presence and absence are related to configurations of the group and to how many sites and subgroups they are located in (Figure 1). These configurations matter in global virtual meetings in terms of across the number of sites other members' involvement (or lack of it) needs to be conveyed (see review on gaze effects on involvement, Ellsworth and Ludwig, 2008). Furthermore, the structure of the interaction and leading practices of global team meetings are also a part of the structural and organisational predictors of social presence in global meetings. If team members cannot participate equally and the team leader or only a few of the members dominate discussions, other participants' attention may decrease. This can happen both in co-located and in virtual meetings, but the structure and leading practices can be more important predictors of social presence in virtual meetings where nonverbal communication and illustrative material could be more difficult to transfer to keep everyone's presence at a high level (Sivunen and Nordbäck, 2015).

Finally, the individual predictors for social presence and social absence among team members during global team meetings may arise from individual members' own levels of interest and motivation regarding the meeting and its topics, 
as well as from their psychological state, such as emotional exhaustion (Reb et al., 2015). Moreover, individuals can also be more or less socially present in the meeting depending on their focus of attention, and whether they share it between multiple simultaneous tasks. Multitasking is often related to the technology and applications that are permanently open even during meetings. These types of software such as instant messaging, social network sites and text messages have a tendency to evoke multitasking by catching participants' attention anywhere and anytime as messages pop up on the screens of laptops or mobile phones (see for example Dennis et al., 2010). This type of technological invasiveness may increase social absence as participant's focus is spreading out to other things than the topics of the meeting (Benbunan-Fich and Truman, 2009). While virtual collaboration tools have enabled participation in meetings from afar, visual access to other participants is often diminished. This in turn lowers the social pressure not to multitask while attending to meetings. (Wasson, 2004.) In addition to multitasking, multiple communication channels in global meeting tools, such as one-on-one text chat, group chat and audio or video connections can be related to social absence. The attention to the team discussion is not always possible if there is for example a simultaneous one-on-one text chat going on within the team members during the global team meeting (see for example Sivunen and Nordbäck, 2015). Therefore, several structural and organisation-related factors, but also individual-level factors, such as team members' motivation, psychological state and multitasking behaviours may predict social presence or social absence in global virtual meetings (see Figure 1). 


\section{Outcomes of Presence and Absence in Global Meetings}

Following the model suggesting predictors of presence and absence in global virtual meetings (Figure 1) I propose a list of structural/organisational and individual outcomes that may be caused by global team members' presence in and absence from global virtual meetings. As the literature shows, many of the effects of physical and virtual presence are similar, and therefore these effects are grouped together in the model (see Figure 1).

Structural/organisational effects related to team members' physical and virtual presence can also be related to opportunities for discussion and agreement in organisation, power and resources across the company and social inclusion across sites. On the other hand, structural/organisational effects related to physical and virtual absence can be related to lack of discussion and agreement across organisational sites, loss of power and resources across organisation (Nurmi, et al., 2009), and social exclusion across sites. Furthermore, even though a team member might be physically present with his or her subgroup at a local site, but was unable for some reason to use the virtual collaboration technology chosen for the team meetings, s/he would not, therefore, be present for the whole team and this often leads to an 'out of sight', out of mind phenomenon (Armstrong and Cole, 2002). The effects of physical and virtual presence and absence may also accumulate into bigger organisation-level benefits or challenges related to knowledge symmetry or asymmetry across various sites.

Individual effects related to physical and virtual presence are manifold. The effects of physical presence of others on individuals' performance have been studied over a long period. As early as in the 19th century, Triplett (1898) published his seminal findings on the presence of other competitors on individual racers' better 
performance. After that, social psychologists have been interested in the effects of present others on individual's performance, phenomena called social facilitation and social inhibition (Aiello and Douthitt, 2001). Zajonc (1965) reviews these studies and defines social facilitation as something in which the physical presence of others facilitates individual's performance, whereas social inhibition is the opposite process of performance decline due to the presence of an audience. The results show that physical presence of others in well-learned tasks enhances performance but may affect the performance negatively on novel tasks (see for example Zajonc, 1965, for a review). Virtual presence has been found to have same kinds of effects, as a study by Hoyt, Blascovich and Swinth (2003) shows. In their study, the perception alone of present, virtual agents in a virtual 3D environment impaired the performance of the individuals. Hence, the physical or virtual presence of others in global team meetings can have effects on individual-level performance in these meetings. Physical and virtual presence may also give voice to individuals, enabling them to voice their opinions and be heard as organisational members.

At the same time, physical and virtual absence can have individual-level effects on those global team members who are physically or virtually absent from global team meetings. These members do not have the possibility to speak out and present their opinions, and they may lose power and resources in the global team. Moreover, physical and virtual absence in global meetings can enable 'social loafing' in the global team. As the team members are more isolated and hence less immediate to one another, their contributions to group activities decrease (see for example Chidambaram and Tung, 2005).

When turning to the last two categories of the model, effects of social presence and social absence in global team meetings (Figure 1), it is worth noting 
that even though many of the current studies on social presence effects have been studied in mediated settings, these effects apply also to physical settings. The global team members sitting face-to-face around the same table during a site visit could experience absent-mindedness and lack of engagement, at least at some point during the meeting, and be socially present and attentive at other times. Likewise, global team members attending to a virtual team meeting from distant sites could be socially engaged or disengaged, at least intermittently, during the global virtual meeting.

The model proposes that structural/organisational effects of social presence are related to the overall commitment to group discussions in global virtual team meetings across organisational sites. Organisational level effects of social presence could also include more informed and ethical decisions (Ruedy and Schweitzer, 2011) and better knowledge sharing throughout the different sites. On an individual level, the predecessors of social presence studies, such as the studies of immediacy by Wiener and Mehrabian (1968), have suggested that certain communicative and language behaviours reduce the psychological distance between the communicators. Thus, global virtual meetings, which have members who participate actively in discussion and respond empathetically to the states of others (that is, behavioural engagement and psychological involvement in social presence terms), might reduce the psychological distance between the global team members. Later findings have also been mainly positive showing that social presence is an important element that affects for example students' satisfaction and enjoyment in online learning situations (see Bulu, 2012 for review). Based on this literature, I propose in the model that the individual-level effects of social presence include reduced psychological distance between the participants and increased meeting satisfaction (see Figure 1). 
The individual level effects of social absence on teamwork are different in nature from the impacts of physical and virtual absence. If a team member is physically or virtually present in a global team meeting but socially absent, it may cause frustration with the other team members. As inattentiveness and unawareness are general attributes of lack of motivation, other team members may challenge the meaningfulness of collaboration with the socially absent team member and question whether s/he should belong to the team at all (Figure 1). The individual level effects of social absence might also have crucial consequences to the future collaboration of the participants and their relationships.

Next, I will draw conclusions from the model of physical, virtual and social dimensions of presence and absence and discuss their implications for leaders and members of global virtual teams.

\section{Conclusion}

This chapter has identified different dimensions of presence and absence in global virtual work and presented a model of the structural/organisation level as well as individual level predictors and effects of these phenomena on virtual team collaboration. The three dimensions of presence and absence in global virtual meetings discussed in this chapter were 1) physical, 2) virtual, and 3) social. Physical presence and absence refer to whether global collaborators share the same physical place or not, and virtual presence and absence relate to their availability in the global meeting via different communication technologies. These two dimensions are more dichotomous than the third level, the social presence/social absence continuum.

The model contributes to the studies of global work and virtual team meetings by expanding the views of presence and absence as a physical or virtual state to 
psychological phenomenon that is fluctuating and can occur in both co-located and mediated settings. By identifying the different dimensions of presence and absence in global virtual meetings the managers of global teams can better select the type of communication technology appropriate to their purpose and ensure that physically absent team members can access the tools and be virtually present in team meetings. Furthermore, by realizing the contextual factors related to social presence and social absence and by understanding the predictors and effects of these phenomena on the team's collaboration, the team leader can better guide the team to achieve an ideal level of social presence within the group during global meetings.

Contrary to some of the theories, which mainly see presence as a more or less static state (for example Short, et al., 1976), the propositional model and perspective I have presented in this chapter suggests that participants' presence and absence are ongoing and fluctuating phenomena, and that the level of social presence and absence, in particular, varies during the global virtual meetings (Sivunen and Nordbäck, 2015). Hence, many of the practical and managerial implications of the propositional model are related to enhancing social presence and diminishing the social absence of participants in global virtual meetings. My propositional model suggests that the consequences of social presence are beneficial both for the global collaborators and their teamwork but also for the global organisation, whereas social absence might cause negative effects on individuals, their collaboration and the global organisation as a whole. Thus, leaders of global virtual meetings should be aware of the predictors and effects of social presence and absence in virtual work and try to enhance participants' social presence in different ways. Scheduling the global meetings in a way that the timing rotates according to the participants' time zones may help in reducing the temporal challenges the 
collaborators may face when participating in the meeting. If the participants have to call in to the global virtual meeting always from their homes in the evenings due to time zone differences, the meeting may overlap with their leisure time activities and optimal presence may not be guaranteed. Therefore, leaders of the meetings may want to schedule them so that they are at optimal times for each of the participants. Furthermore, leaders of global virtual meetings may want to consider how to structure the meetings in a way that social presence is possible for all participants, regardless of whether they are physically or virtually present in the meeting. Sharing speech turns equally, supporting the meetings with illustrative materials, helping the virtual collaborators to access the used online tools, and showing one's own availability and presence in the meeting are ways through which leaders of global virtual meetings can support and enhance participants' social presence (see also Sivunen and Nordbäck, 2015).

The model presented in this chapter also has implications related to virtual meeting technology. Some collaboration tools already contain technical signals that try to demonstrate participants' social presence during the meeting. Signals indicating participants' presence or absence include various automatic status signs (online, away, offline) that are being displayed on, for example, users' instant messaging programmes, depending on the online activities or based on participant's schedule in his/her electronic calendar. In 3D virtual environments, there are virtual representations of the participants, avatars, which automatically react to their users' online behaviour (for example, avatar's head bobs as a sign of falling asleep if the user does not move his/her mouse for a while), and they can provide approximate awareness of other members' virtual presence. Nevertheless these technical signals cannot provide accurate information on the participants' psychological involvement 
and behavioural engagement, that is, social presence, at that particular moment. Therefore, managerial as well as participants' attentiveness to and awareness of their own and others' social presence in global virtual meetings play an important role in how well these meetings succeed. 
References

Aiello DA, Douthitt EA (2001) Social facilitation from Triplett to electronic performance monitoring. Group Dynamics: Theory, Research and Practice 5(3): 163-180.

Aiello DA, Kolb KJ (1995) Electronic performance monitoring and social context: Impact on productivity and stress. Journal of Applied Psychology 80(3): 339_ 353.

Armstrong DJ, Cole P (2002) Managing distances and differences in geographically distributed work groups. In: Hinds P, Kiesler S (eds) Distributed Work. Cambridge, MA: MIT Press, 167-186.

Ballard DI, Tschan F, and Waller MJ (2008) All in the timing: Considering time at multiple stages of group research. Small Group Research 39(3): 328-351.

Barmby TA, Ergolani MG, and Treble JG (2002) Sickness absence: An international comparison. The Economic Journal 112(June): F315-F331.

Barthe B, Messing K, and Abbas L (2010) Strategies used by women workers to reconcile family responsibilities with atypical work schedules in the service sector. Work 40(2010): S47-S58.

Baxter LA, Braithwaite DO, Golish TD, and Olson LN (2002) Contradictions of interaction for wifes of elderly husbands with adult dementia. Journal of Applied Communication Research 30(1): 1-26.

Benbunan-Fich R, Truman GE (2009) Multitasking with laptops during meetings, Communications of the ACM 52(2): 139-141.

Betz G, Thorngren JM (2006) Ambiguous loss and the family grieving process. The Family Journal 14(4): 359-365. 
Biocca F, Harms C, and Gregg J (2001) The networked minds measure of social presence: Pilot test of the factor structure and concurrent validity. Paper presented at the 4th Annual International Workshop on Presence, Philadelphia, PA, May 21-23, 2001.

Biocca F, Harms C, and Burgoon JK (2003) Toward a more robust theory and measure of social presence: Review and suggested criteria. Presence 12(5): 456-480.

Bond CF, Titus LJ (1983) Social facilitation: A meta-analysis of 241 studies. Psychological Bulletin 94(2): 265-292.

Bulu ST (2012) Place presence, social presence, co-presence, and satisfaction in virtual worlds. Computers \& Education, 58(1): 154-161.

Chidambaram L, Tung LL (2005) Is out of sight, out of mind? An empirical study of social loafing in technologically-supported groups. Information Systems Research 16(2):149-168.

Chudoba KM, Wynn E, Lu M, and Watson-Manheim MB (2005) How virtual are we? Measuring virtuality and understanding its impact in a global organization. Information Systems Journal 15(4): 279-306.

Dennis AR, Rennecker JA, and Hansen S (2010) Invisible whispering: Restructuring collaborative decision making with instant messaging. Decision Sciences, 41(4): 845-886.

Ellsworth PC, Ludwig LM (2008) Visual behavior in social interaction. In: Mortensen CD (ed.) Communication Theory (2nd edn). New Brunswick, N.J.: Transaction Publishers, 246-272.

Engström LG, Jansson S (2009) Predictors of work presence - Sickness absence in a salutogenic perspective. Work 33(3): 287-295. 
Fisher S, Hood B (1987) The stress of the transition to university: A longitudinal study of psychological disturbance, absent-mindedness, and vulnerability to homesickness. British Journal of Psychology 78(4): 425-441.

Fulk J, Steinfeld C, Schmitz J, and Power JG (1987) A social information processing model of media use in organizations. Communication Research 14(5): 529_ 552.

Gibson CB, Gibbs JL (2006) Unpacking the concept of virtuality: The effects of geographic dispersion, electronic dependence, dynamic structure, and national diversity on team innovation. Administrative Science Quarterly 51(3): 451-495.

Goffman E (1963) Behavior in Public Places. New York: The Free Press.

Grinyer A, Singleton V (2000) Sickness absence as risk-taking behaviour: A study of organisational and cultural factors in the public sector. Health, Risk \& Society 2(1): 7-21.

Halbesleben JRB, Whitman MV, and Crawford WS (2014) A dialectical theory of the decision to go to work: Bringing together absenteeism and presenteeism. Human Resource Management Review 24(2): 177-192.

Henchy T, Glass DC (1968) Evaluation apprehension and the social facilitation of dominant and subordinate responses. Journal of Personality and Social Psychology 10(4): 446-454.

Hinds PJ, Cramton CD (2014) Situated coworker familiarity: How site visits transform relationships among distributed workers. Organization Science 25(3): 794814.

Hinds PJ, Weisband SP (2003) Knowledge sharing and shared understanding in virtual teams. In: Gibson CB, Cohen SB (eds) Virtual Teams that Work: 
Creating Conditions for Virtual Team Effectiveness. New York: Jossey-Bass, 21-36.

Hoyt CL, Blascovich J, and Swinth KR (2003) Social Inhibition in immersive virtual environments. Presence 12(2): 183-195.

Irvine A (2011) Fit for work? The influence of sick pay and job flexibility on sickness absence and implications for presenteeism. Social Policy \& Administration 45(7): 752-769.

Johns G (2010) Presenteeism in the workplace: A review and research agenda. Journal of Organizational Behavior 31(4): 519-542.

Kahn WA (1990) Psychological conditions of personal engagement and disengagement at work. Academy of Management Journal 33(4): 692-724.

Kahn WA (1992) To be fully there: Psychological presence at work. Human Relations 45(4): 321-349.

Lombard M, Ditton T (1997) At the heart of it all: The concept of presence. Journal of Computer-Mediated Communication 3(2). Available at: http://jcmc.indiana.edu/vol3/issue2/lombard.html

MacGregor JN, Cunningham JB, and Caverley N (2008) Factors in absenteeism and presenteeism: Life events and health events. Management Research News, 31(8): 607-615.

Martins LL, Gilson LL, and Maynard MT (2004) Virtual teams: What do we know and where do we go from here? Journal of Management 30(6): 805-835.

Nurmi N (2010) Work stressors related to geographic distance and electronic dependence in virtual teams. International Journal of Business and Systems Research 4(3): 311-329. 
Nurmi N, Bosch-Sijtsema PM, Sivunen A, and Fruchter R (2009) Who shouts louder? Exerting power across distance and culture. In: Proceedings of the 2009 International workshop of intercultural collaboration, Stanford, CA: ACM, 7180.

O’Leary MB, Mortensen M (2010) Go (con)figure: Subgroups, imbalance, and isolates in geographically dispersed teams. Organization Science 21(1): 115131.

Panteli N (2004) Discursive articulations of presence in virtual organizing. Information and Organization, 14(1): 59-81.

Pauleen DJ, Yoong P (2001) Facilitating virtual team relationships via internet and conventional communication channels. Internet Research 11(3): 190-202.

Pendharkar PC (2013) Genetic learning of virtual team member preferences. Computers in Human Behavior, 29(4): 1787-1798.

Reb J, Narayanan J, and Ho ZW (2015) Mindfulness at work: Antecedents and consequences of employee awareness and absent-mindedness. Mindfulness, 6(1): 111-122.

Ruedy NE, Schweitzer ME (2011) In the moment: The effect of mindfulness on ethical decision-making. Journal of Business Ethics 95(1): 73-87.

Ruppel CP, Gong B, and Tworoger LC (2013) Using communication choices as a boundary-management strategy: How choices of communication media affect the work-life balance of teleworkers in a global virtual team. Journal of Business and Technical Communication 27(4): 436-471.

Sivunen A, Nordbäck E (2015) Social presence as a multi-dimensional group construct in 3D virtual environments. Journal of Computer-Mediated Communication 20(1): 19-36. 
Sivunen A, Valo M (2006) Team leaders' technology choice in virtual teams. IEEE Transactions on Professional Communication 49(1): 57-68.

Shen NK, Khalifa M (2008) Exploring multidimensional conceptualization of social presence in the context of online communities. International Journal of Human-Computer Interaction 24(7): 722-748.

Short J, Williams E., and Christie B (1976) The Social Psychology of Telecommunications. London: Wiley.

Stanton JM, Barnes-Farrell JL (1996) Effects of electronic performance monitoring on personal control, task satisfaction, and task performance. Journal of Applied Psychology 81(6): 738-745.

Swigger K, Hoyt M, Serçe FC, Lopez V, and Alpaslan FN (2012) The temporal communication behaviors of global software development student teams. Computers in Human Behavior 28(2): 384-392.

Triplett N (1898) The dynamogenic factors in pacemaking and competition. The American Journal of Psychology 9(4): 507-533.

Venkatesh V, Morris MG, Davis GB, and Davis FD (2003) User acceptance of information technology: Toward a unified view. Management of Information Systems Quarterly 27(3): 425-478.

Wasson C (2004) Multitasking during virtual meetings. Human Resource Planning 27(4): 47-60.

Wiener M, Mehrabian A (1968) Language within Language: Immediacy, a Channel in Verbal Communication. New York: Appleton-Century-Crofts.

Zajonc RB (1965) Social facilitation. Science 149(3681): 269-274. 